\title{
Recent Advances in Valorization Methods of Inorganic/Organic Solid, Liquid, and Gas Wastes
}

\author{
Licínio M. Gando-Ferreira, ${ }^{1}$ Faïçal Larachi, ${ }^{2}$ and Santiago Esplugas ${ }^{3}$ \\ ${ }^{1}$ Department of Chemical Engineering, University of Coimbra, Sílvio Lima street, 3030-790 Coimbra, Portugal \\ ${ }^{2}$ Department of Chemical Engineering, Laval University, 1065 la Médecine Avenue, Québec, QC, Canada G1V 0A6 \\ ${ }^{3}$ Departmento d'Enginyeria Quimica, Universitat de Barcelona, Marti i Franques 1, 08028 Barcelona, Spain
}

Correspondence should be addressed to Licínio M. Gando-Ferreira, lferreira@eq.uc.pt

Received 2 April 2012; Accepted 8 April 2012

Copyright (c) 2012 Licínio M. Gando-Ferreira et al. This is an open access article distributed under the Creative Commons Attribution License, which permits unrestricted use, distribution, and reproduction in any medium, provided the original work is properly cited.

The main goal of this special issue was to gather contributions dealing with the latest breakthrough methods for providing value compounds and energy/fuel from waste valorization. Valorization is a relatively new approach in the area of industrial wastes management, a key issue to promote sustainable development. In this field, the recovery of valueadded substances, such as antioxidants, proteins, vitamins, and so forth, from the processing of agroindustrial byproducts, is worth mentioning. Another important valorization approach is the use of biogas from waste treatment plants for the production of energy. Several approaches involving physical and chemical processes, thermal and biological processes that ensure reduced emissions and energy consumptions were taken into account. The papers selected for this topical issue represent some of the mostly researched methods that currently promote the valorization of wastes to energy and useful materials. As such, they provide interesting and timely research results in that field that we have the pleasure to share with the readers. We would like to thank all the authors for submitting their nice papers and all the referees for their excellent feedback.

This special issue includes eight papers, where one paper is related to the production of energy from biomass, and four papers cover application of advanced oxidation processes and of biological sorbents for the treatment of wastewaters. One paper addresses the rapid stabilization of organic wastes during the composting process and another utilization of agrowastes for preparation of PCV-based composites. Finally, one paper presents a technoeconomic analysis for production of value-added compounds from wastewaters.
In the paper entitled "Biofuels production from biomass by thermochemical conversion technologies," Verma et al. presents a brief review on various available technologies for thermochemical conversion of biomass into biofuels that can be used as alternatives to fossil fuels. Some advantages of utilizing biomass pyrolysis for production of sustainable energy in comparison to combustion and gasification are also reported in this paper.

In the paper "Titanium dioxide-mediated photocatalysed degradation of two herbicide derivatives chloridazon and metribuzin in aqueous suspensions," Khan et al. propose the advanced oxidation process with $\mathrm{TiO}_{2}$ photocatalyst for the degradation/mineralization of two herbicides in aqueous suspensions. They demonstrate that in the case of CHL the highest degradation efficiency is achieved at $\mathrm{pH} 3.2$, whereas for MET better degradation conditions are attained under alkaline conditions.

In the work entitled "Degradation of abamectin using the photo-fenton process," Thiago et al. investigate the application of photo-Fenton process for the degradation of abamectin that is the active principle of one of most commonly used pesticides in the cultivation of strawberries. Their experiments showed that $70 \%$ of the initial load of the compound existent in water samples is removed after 60 minutes of UV radiation.

In the paper "Utilization of agrowaste polymers in pvc/nbr alloys: tensile, thermal, and morphological properties," Ahmad et al. examine tensile properties of poly(vinyl chloride)PVC/nitrile butadiene-NBR formulations with wood fluor (WF), a natural byproduct from olive oil extraction industry. 
They concluded that WF loading improves the tensile modulus of the blend, whereas the tensile strength is kept approximately constant.

The research of Nduka entitled "Application of chemically modified and unmodified waste biological sorbents in treatment of wastewater" focuses on the removal of pollutants of the textile industry and heavy metals contained in wastewaters using protein and cellulosic wastes. He presents high efficiencies in the detoxification of wastewater as dependent on the particle size of cellulosic waste sorbents and contact time.

In the paper "Valorization of agroindustrial wastes as biosorbent for the removal of textile dyes from aqueous solutions," Contreras et al. study the technical feasibility of using agroindustrial wastes for adsorption of dyes. Their results based on equilibrium isotherms and kinetic tests have shown that those biosorbents have significant potential for removal of basic dyes from aqueous solutions.

In the paper "Use of iron (II) salts and complexes for the production of soil amendments from organic solid wastes," Beneduci et al. propose the use of iron (II) ions in the oxidative decomposition process of solid wastes. It was demonstrated that these ions significantly enhance the extent of the oxidation process as evaluated from the value $\mathrm{C} / \mathrm{N}$ ratio.

In the paper entitled "High-added value materials production from OMW: A technical economical optimization," Arvaniti et al. present a technoeconomic analysis for the treatment of olive mill wastewater (OMW) using the integration of membranes processes, namely, ultrafiltration, nanofiltration and reverse osmosis. They have shown that the utilization of isolated OMW fractions in fertilizers or in ecological herbicides can depreciate the total cost for a period of approximately five years.

\section{Acknowledgment}

The guest editors are also sincerely thankful to the editorial staff for the support, guidance, and efforts in welcoming this series of papers on a timely subject.

Licínio M. Gando-Ferreira Faïçal Larachi Santiago Esplugas 

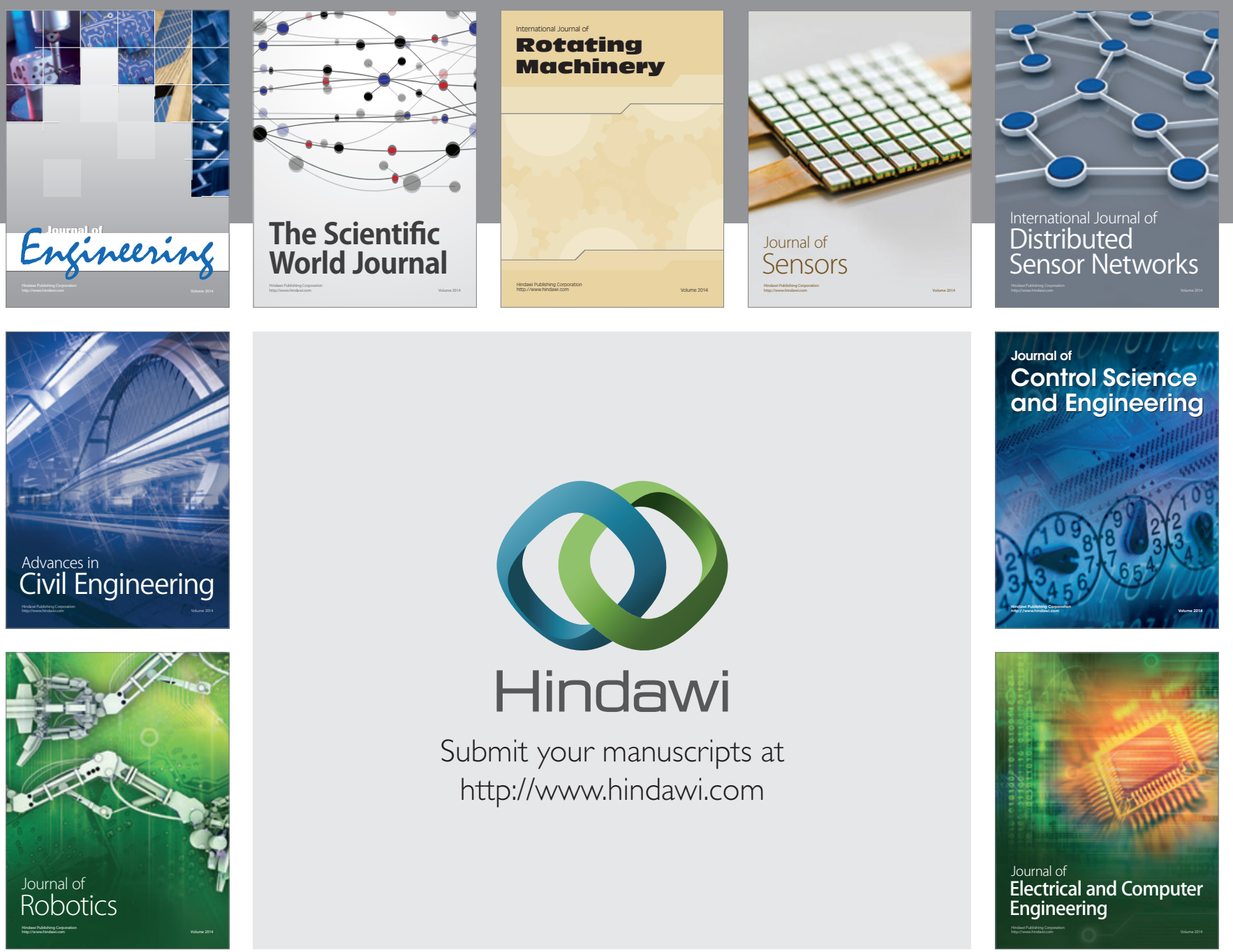

Submit your manuscripts at

http://www.hindawi.com
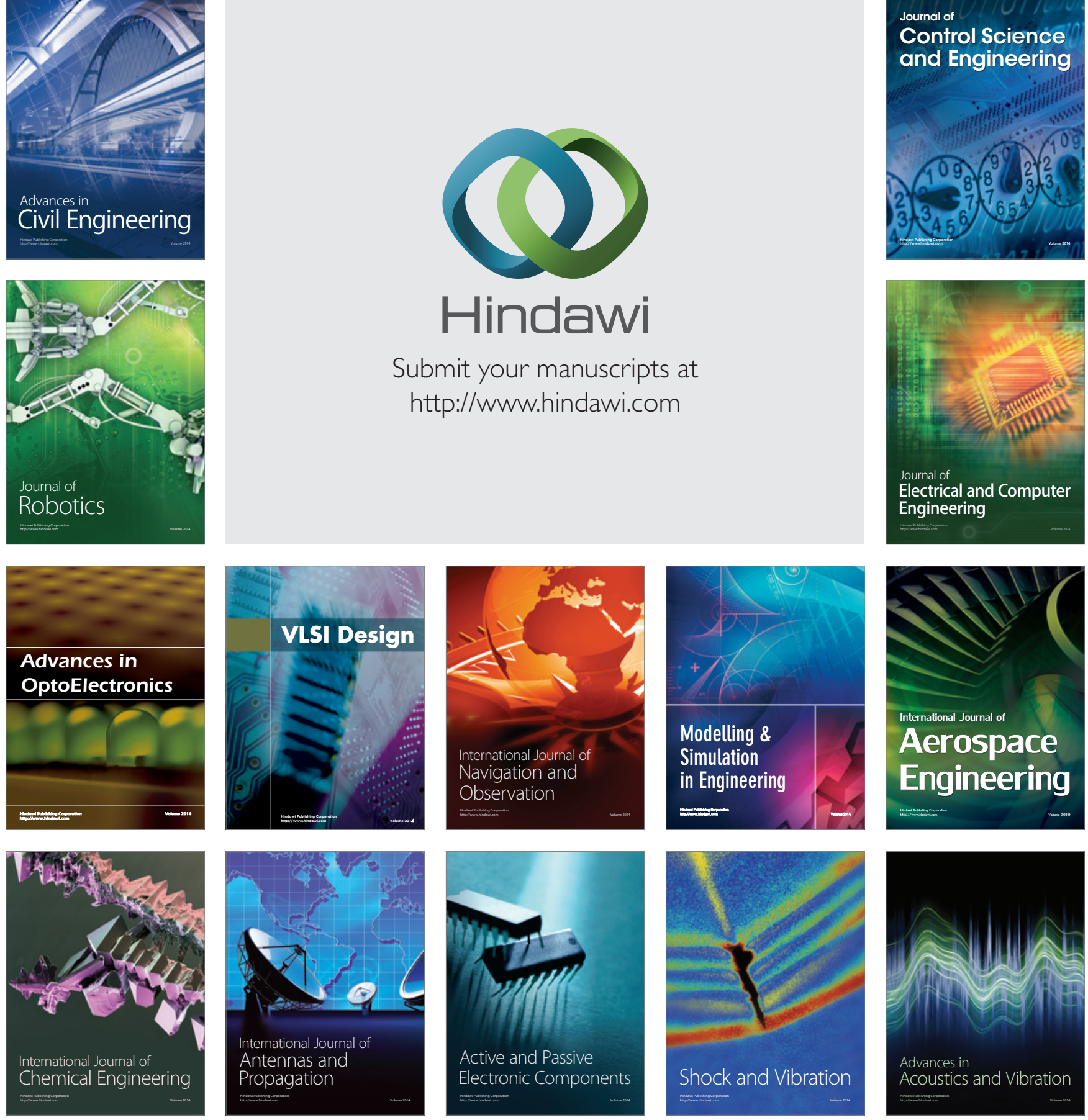